\title{
A Systematic Review on City Liveability Global Research in the Built Environment: Publication and Citation Matrix
}

\author{
Mastura Adam ${ }^{1 *}$, Norafida Ab Ghafar ${ }^{1}$, Abubakar Ahmed $^{2}$, and Keumala Nila ${ }^{1}$ \\ ${ }^{I}$ The Centre for Building, Construction \& Tropical Architecture (BuCTA). Faculty of Built \\ Environment, University of Malaya, 50603, Kuala Lumpur, Malaysia \\ ${ }^{2}$ Department of Architecture, Faculty of Earth and Environmental Sciences (FAEES), \\ Kano University of Science and Technology, Wudil, Kano, Nigeria. \\ *mastura@um.edu.my
}

\begin{abstract}
This study is an investigation of urban liveability issues in the city development. The study focuses on the appraisal of global research output on urban liveability over the period of 35 years (1980-2015). Bibliometric methods had been carried out to identify and evaluate the productivity of top authors, document types, journals, countries, affiliations, and sources. Data were extracted from scholarly literature published in the leading indexing databases namely Thomson Reuter's Web of Science and Elsevier's SciVerse Scopus. In this note, a quantitative review of the outstanding global research output in the liveability related field to show a major trend of research and shed light on future direction. Data were analysed, presented and discussed the common characteristics in the top journals, hot, and highly cited articles and the focus areas including common keywords across the studies, researched and under-researched fields. The results revealed, ever since 2005, liveability research output is steadily increasing, with 2015 as the most prolific year. Australia, England, and the USA are the most productive countries. Urban Geography, Urban Design International, and International Development Planning Review are the leading journals in the field. While continuous research interest is prevalent in liveability related field with global collaborative potentials, areas receiving the least research attention such as urban transportation, education, and resiliency could give a directional trend for future urban studies. Liveability Research Matrix established in this research were aimed to guide future research in finding the gap across global context, areas and multi-disciplinary.
\end{abstract}

Keywords: urban liveability; bibliometric; research gap, global collaboration, research matrix

\section{INTRODUCTION}

Liveability as a concept has acquired various meanings, ranging from the decision people make about where they choose to live, to the recent language of planning for a better place to live. In the former liveability is enshrined in defence mechanism against disaster in an urban environment (Adam et al, 2016; Islam et al., 2016; Palmary et al., 2003), accessibility for everyone, socioeconomic, political and social inclusion (Sauter and Huettenmoser, 2008). In the latter liveability becomes a novel context of unrestricted development in a sustainable way (Newton, 2012). These contain the exploration of the social determinants of health (Badland et al., 2014) and a better physical utilization of spaces (Hunt et al., 2016). Generally, liveability covers areas including the environment, medicine, agriculture, geography, transportation, architecture, and planning. Thus, liveability cut across humanities, art, science and social sciences. Consequently, liveability has become the focus of much research attention recently with global collaborative potentials.

In the world of research, however, liveability suggests high but unsustainable consumption of resources, which pose sociotechnical challenges (Newton, 2012). Thus, liveability is interchangeable with sustainability and resiliency paradigm. On the platform of sustainability, liveability is typically viewed as an option improvement for sprawling suburbs with limited resources and population explosion (McCrea and Walters, 2012). Accordingly, terminologies like urban compaction, environmental quality, and neighbourhood satisfaction are just some of the criteria for assessing the most liveable cities in the developed world (Howley et al., 2009). Under the auspices of resiliency, liveability responds to environmental problems and disaster management (de Jong et.al, 2009), ability to withstand and recover from shock (Leichenko, 
2011), safety from danger, violence, and crime (Sauter and Huettenmoser, 2008; Pantuliano et al., 2012). In these climes, people liveability concern is to avoid isolation, slums, scarcity, homelessness and infrastructural deficit, particularly in the less developed world. In between these two dipoles are the developing countries whose main concern is to attain the enhanced status by striking a balance between urban sustainability and resiliency (Shamsuddin et al., 2012) and avoid the problems associated with underdevelopment.

The tendency has gone to consider an environment as liveable with reference to its ability to meet people with basic needs. Correspondingly, knowledge of the characteristics of effective urban space and the milestone recorded in the research domain is the key ingredient required by researchers in the field. The wide-ranging meaning of urban liveability presented by many researchers only reinforced the need for a more systematic evaluation of the multiple ideas of liveability under one umbrella. Yet, until now hardly any data on liveability research output has been collected. Bibliometric analysis is not a new way of evaluating research output. It has been utilized extensively with different terminologies (Harzing, 2010; Gul et al., 2015). Thus, the bibliometric analysis could provide guidance not only to the novice researcher in the field but also could show a trend of research in the field. Thus, this research intended to cross examine the global research output on urban liveability.

\section{LITERATURE REVIEW}

\subsection{Overview of Current Liveability Research}

Liveability is a term, which has been used ever since, however, we have not found in the literature, its use in relation to cities before the 1980s. Thereafter, the concept of "liveable cities" becomes distinctly meaningful in assessing the performance of cities in supporting the best or the worst standard of living. This has allowed the understanding of liveability to differ across different geographical zones. Of this variation, the understanding of what constitute the most liveable city is not the challenge, but to discover an acceptable criterion for the selection process. The criteria ought to be allinclusive. To this end, various ranking approaches are postulated. Prominent among such includes the ranking process used by the Economist. Their five criteria include:
Availability and quality of public and private: (i) healthcare indicators (20\%), (ii) education indicators $(10 \%)$, (iii) infrastructure $(20 \%)$, and (iv) relative stability $(25 \%)$, as well as (v) Culture and environment (25\%) including weather and climate, level of corruption and cultural and sporting activities. Thus, studies in liveability field ought to cover these areas and beyond.

\subsection{Systematic Review using Bibliometric Analysis Method}

Bibliometric is a method to review and analyze the development of disciplines and/or fields by organizing thick rich data which include citations, author affiliations, keywords, themes, and methods employed for published studies in the disciplines through advanced statistical techniques (McBurney and Novak, 2002). Bibliometric methods had been utilized in various studies to enlightened research methods, prolific and productive scholars, institutions, countries, the knowledge domain by year and specific research focus and themes within disciplines (Chan and Hsu, 2016; Gregory and Weinland, 2016; Landström et al., 2012).

\section{RESEARCH METHODOLOGY}

Two steps are required to assess the global research output in the liveability field: first, is the extraction of data from reliable sources. The second step is harmonizing similar data and comparing sources of the research output as presented in what follows. Data were based on Thomson Reuter's Web of Science (WoS) core collection database extraction and Elsevier's SciVerse Scopus (Scopus), owing to their reliability, authenticity, and exhaustive coverage (Adriaanse and Rensleigh, 2013; BarIlan, 2008; Levine-Clark and Gil, 2009). It has become the norm to use keywords to evaluate scientific research in recent years (Chiu et al., 2007; Xie et al., 2008). We search for liveability and liveable using a search string "liveab*" trailing wildcard query from "topic" indexing.

Since the two indexing databases selected are not mutually exclusive, data overlap was apparent. WoS and Scopus records were then downloaded into MS-excel separately for analysis. Information extracted are associated with the category of record counts selection, which includes by the author, country, year, document, affiliation, and citation. Data 
extraction process, used, is diagrammatically

illustrated in Figure 1.

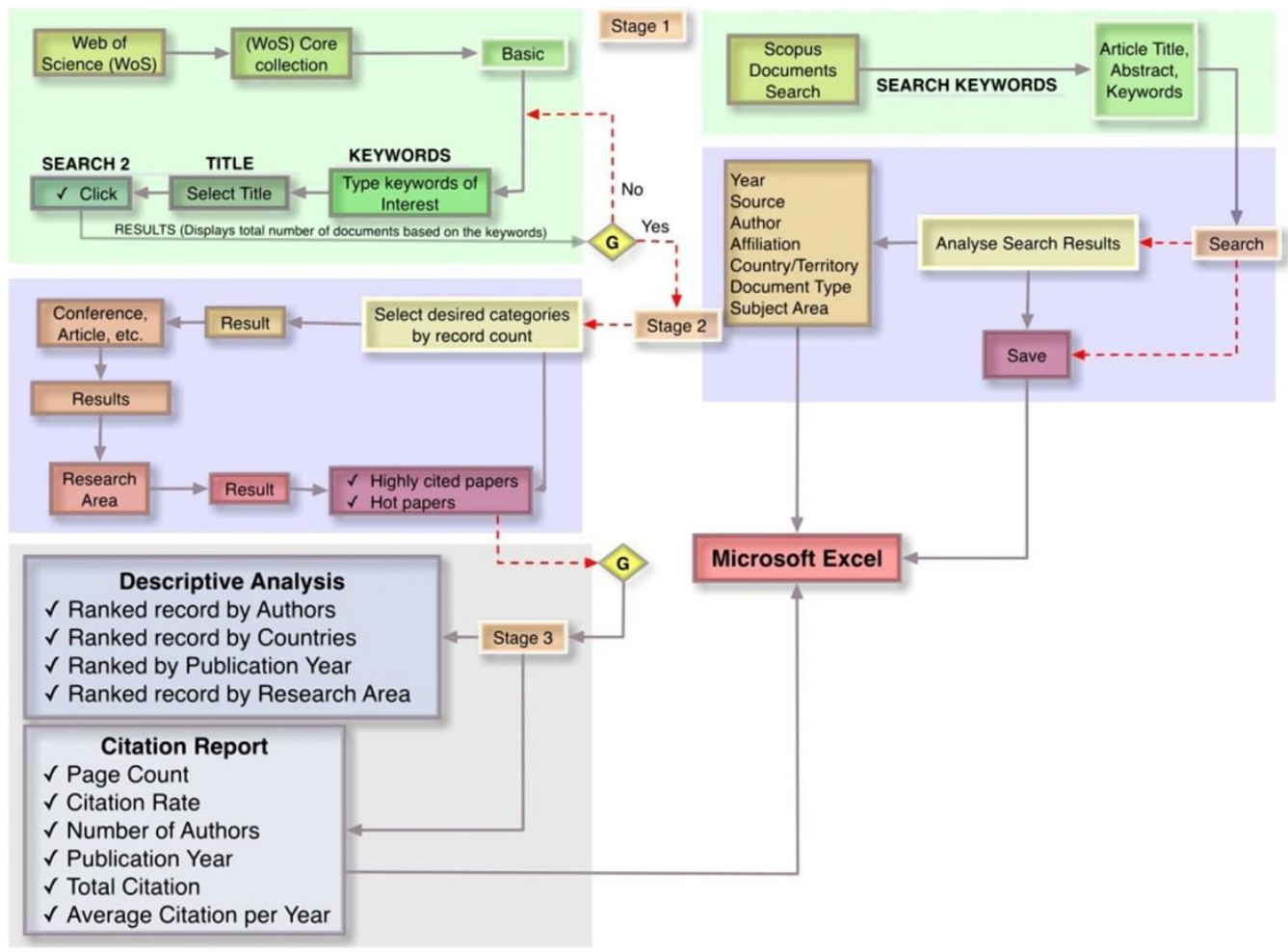

Figure 1: Systematic Data Extraction Stages and Processes

\section{RESULTS}

\subsection{Publication Output of Document per Year}

While the data extracted from the WoS core collection amounted to 441 documents, the Scopus database returned 781 documents when distribution per year was uneven. Afterward, articles publication output started rising and exceeded 10 per year as shown in Figure $2 \mathrm{~b}$. Evidently, $85.5 \%$ of articles published, through the three and a half decades are concentrated within the year range of 2005-2015. The number of documents per publication year, top articles, and authors based on citation and record counts was then extracted for a more indepth analysis. We then exported the top 10 articles based on record and citation counts and included the highly cited and hot articles for further analysis. Articles from the top cited authors with three or more record counts were found prevalent.

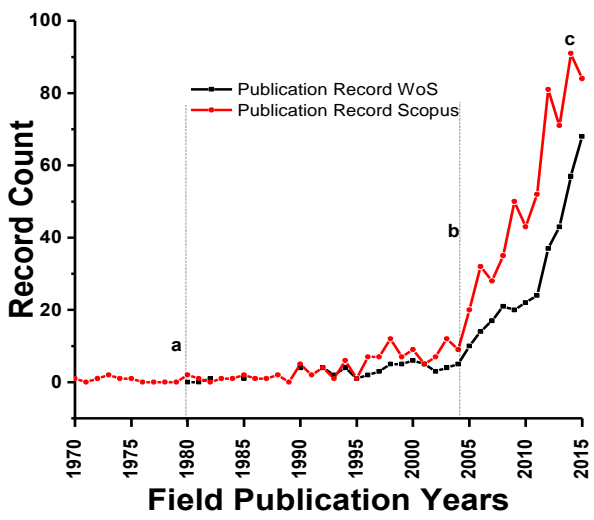

Figure 2: (a) Distribution record count published per publication year.

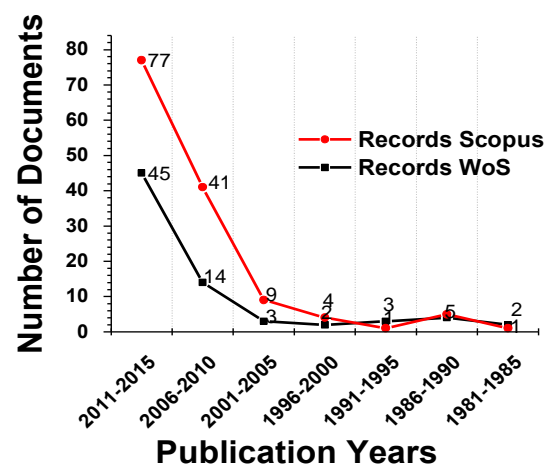

Figure 3: (b) Distribution of documents published per publication year. 


\subsection{Publication Output Based On Document Type}

Results for the documents type in the liveability related field reported in the two eminent databases indicated a number of publications from the article $67.26 \%$ and reviews $4.45 \%$, collectively totalling $(71.71 \%)$. In the Scopus database, however, articles, articles in press and reviews are $63.25 \%$, $1.66 \%$ and $5.63 \%$ respectively totalling $70.54 \%$ as shown in Table 1 .

\subsection{Publication Output Based on Subject Area Category}

Social Science category covered the highest record based on the research by subject area coverage in the field followed by engineering, then environmental science ecology and business economics in the WoS database. In the Scopus database, however, urban studies, environmental science ecology, geography, architecture, public administration, engineering, and then social science/ "social science other topics" are the predominant subject areas. The cumulative result from the two outstanding databases shows social science and "social science other topics" as the predominant subject areas, followed by the environmental science ecology, engineering, and business economics. Moreover, agriculture/biological Science, biomedical science medicine, material science, and art and humanities are the least researched in the urban liveability field as shown in Figure $3 \mathrm{a}$.

Table 1: Distribution of document publication output based on document types

\begin{tabular}{lllll}
\hline Document Type & Record WoS & Percentage & Records Scopus & Percentage \\
Article & 302 & 67.26 & 63.25 \\
Article in Press & - & - & 13 & 1.66 \\
Review & 20 & 4.45 & 44 & 5.63 \\
Proceedings Paper & 98 & 21.83 & 134 & 17.16 \\
Conference Review & - & - & 4 & 0.51 \\
Book Chapter & - & - & 60 & 7.68 \\
Book Review & 11 & 2.45 & - & - \\
Book & - & - & 23 & 2.94 \\
Editorial Material & 8 & 1.78 & 3 & 0.38 \\
Short Survey & - & - & 2 & - \\
Note & 4 & 0.89 & 3 & - \\
Meeting Abstract & 4 & 0.89 & - & 0.13 \\
Letter & 2 & 0.45 & 1 & 0.64 \\
Note & 4 & 0.89 & 3 & -
\end{tabular}

\subsection{Publication Output Based on Institutional Contributions}

Just as every independent contributor has the right to be included or acknowledged in the authorship of a manuscript (Coats, 2009), so also are the institutions or organizations of author's affiliations and the country itself as they are the host and funding sources of the research. Moreover, accumulation of citation by institutions helps in raising its standard (Falagas et al., 2013). We present the distribution of productive articles on the subject of liveability related researchers in Figure $3 \mathrm{~b}$. Finding revealed that the most prolific Universities in the WoS core collection as the University of Melbourne followed by University Western Australia, and then University Technology Malaysia. Under the Scopus, however, National University 
Singapore have displayed a significant research output, followed by the University of Melbourne and University Western Australia and Monash University. Aggregate, National University Singapore, University of Melbourne, University Western Australia followed by Monash University and University of Technology Malaysia and then the Swinburne University of Technology are predominant as shown in Figure $3 b$.

\subsection{Publication Output of the Most Prolific Countries}

It is clear that the most productive countries, measured by publication count and citation count are Australia, the UK, and then the USA as shown in Figure 4. The privileged performance of Australia, the UK, and the USA may be due to high liveability investment, which earned them a high rating in the liveability ranking by the Economist. Other countries productivity in the field is based on author's cumulative citation and can be seen more elaborately following this link:

http://www.openheatmap.com/view.html?map =NonpreparatoryCatchpollMismarry

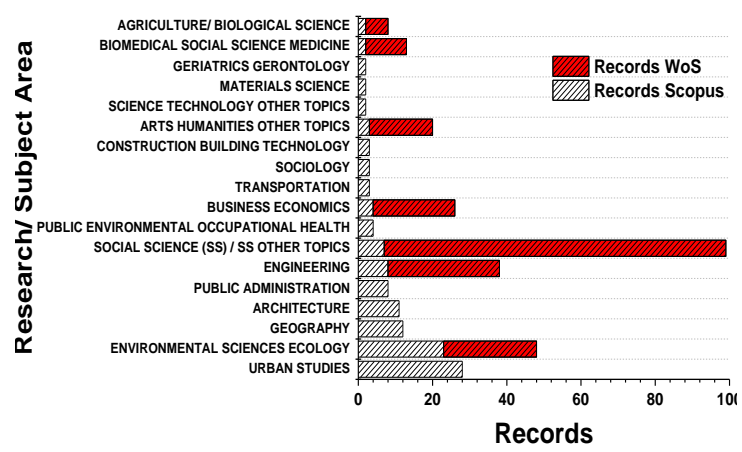

Figure 4: (a) distribution of data based on the subject/ research area category

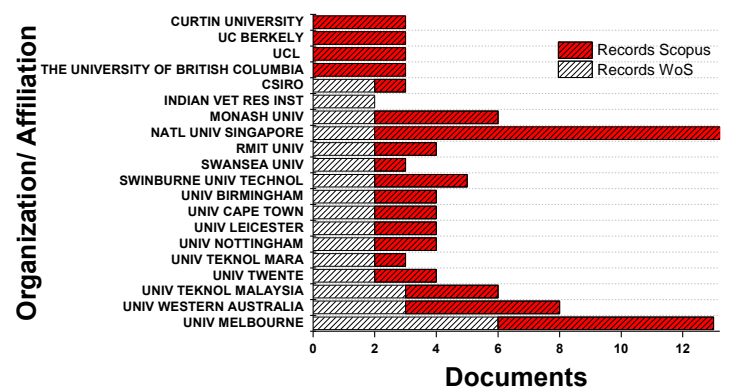

Figure 5: (b) organization/ institutional contribution/ affiliation

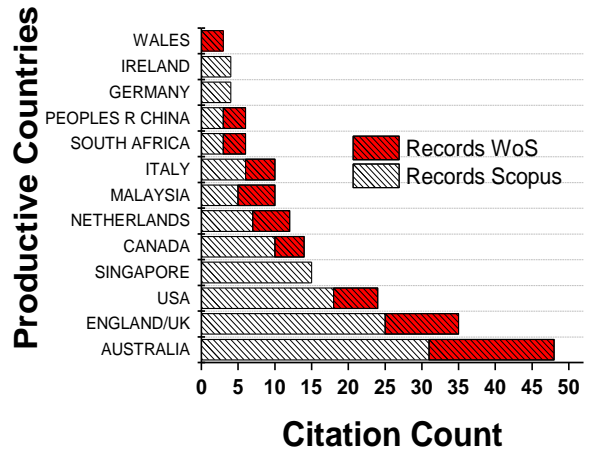

Figure 4: Countries productivity measured by citation count

\subsection{Publication Output of the Top Journals in The Field}

Town Planning Review is the most prolific in this field followed by urban geography, urban design international, Procedia Social and Behavioral Sciences and then open house international and public transport international in the WoS journals. In the Scopus, however, Urban Geography is topping followed by urban design international, then international development planning review as shown in Figure 5.

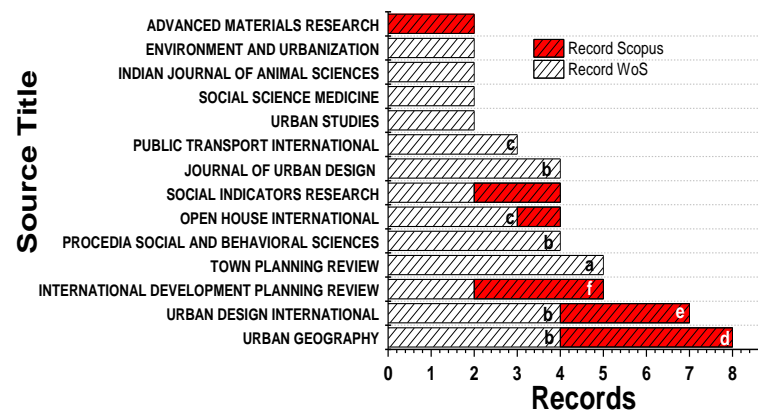

Figure 5: Top journals in the field

\subsection{Publication Output Based on Articles Citation Records}

We discovered that not a single article in this field received a citation in the WoS database published before 2001. Conversely, ever since 2001 no publication year recorded less than five articles in the Scopus database. We also discovered that from 2007 citation escalates in this field. Thus, 2015 was the most fruitful year with more articles contributing in the field than any predecessor year. A highly cited paper (Badland et al., 2014) was first published in 2014. Thereafter, a promising article in the field received highly cited and a hot article 
recognition and was published recently in 2016 (Hunt et. al, 2016). Other notable and top cited articles in the field are presented in Figure 5 alongside the hot article and the highly cited ones as shown in Table 2. Thus, we provide a review of the highly focused area and the most frequently used keywords in the top articles in the field for the benefit of researchers in this field as indicated in Table 3.

Table 2: Citation matrix across article title, top authors and top, highly, and hot articles that received more citations in the field of liveability

\begin{tabular}{|c|c|c|c|c|c|}
\hline $\mathbf{S} / \mathbf{N}$ & Article Title & Top Authors & $\begin{array}{l}\text { Record } \\
\text { WoS }\end{array}$ & $\begin{array}{l}\text { Record } \\
\text { Scopus }\end{array}$ & $\begin{array}{l}\text { Essential Science } \\
\text { Indicator (ESI) }\end{array}$ \\
\hline 1 & Liveable cities and urban underground space. & Hunt (2016) & 3 & 3 & $\begin{array}{l}\text { Highly Cited \& } \\
\text { Hot Paper }\end{array}$ \\
\hline 2 & $\begin{array}{l}\text { Urban liveability: emerging lessons from } \\
\text { Australia for exploring the potential for } \\
\text { indicators to measure the social determinants } \\
\text { of health. }\end{array}$ & $\begin{array}{l}\text { Badland, Whitzman } \\
\text { (2014) }\end{array}$ & 17 & 18 & Highly/ Top Cited \\
\hline 3 & $\begin{array}{l}\text { Impacts of urban consolidation on urban } \\
\text { liveability: Comparing an inner and outer } \\
\text { suburb in Brisbane, Australia. }\end{array}$ & $\begin{array}{ll}\text { McCrea } & \text { and } \\
\text { Walters (2012) }\end{array}$ & 8 & 16 & \\
\hline 4 & $\begin{array}{l}\text { Liveable and sustainable? Socio-technical } \\
\text { challenges for twenty-first-century cities. }\end{array}$ & Newton (2012) & 13 & 19 & \\
\hline 5 & $\begin{array}{l}\text { Designing a liveable compact city: Physical } \\
\text { forms of city and social life in urban } \\
\text { neighbourhoods }\end{array}$ & Raman (2010) & 13 & 16 & \\
\hline 6 & $\begin{array}{l}\text { Sustainability versus liveability: an } \\
\text { investigation of neighbourhood satisfaction. }\end{array}$ & $\begin{array}{l}\text { Howley, } \quad \text { Scott } \\
(2009)\end{array}$ & 31 & 47 & Top Cited \\
\hline 7 & Liveable streets and social inclusion & $\begin{array}{l}\text { Sauter and } \\
\text { Huettermoser } \\
(2008)\end{array}$ & 14 & 14 & \\
\hline 8 & $\begin{array}{l}\text { Horizon } 3 \text { planning: meshing liveability with } \\
\text { sustainability. }\end{array}$ & Newton (2012) & 12 & 16 & \\
\hline 9 & $\begin{array}{l}\text { Conflicts of Liveability in the 24-hour City: } \\
\text { Learning from } 48 \text { Hours in the Life of } \\
\text { London's Soho }\end{array}$ & $\begin{array}{l}\text { Roberts and Turner } \\
(2005)\end{array}$ & & 44 & \\
\hline 10 & Measuring the liveable city. & Southworth (2003) & & 17 & \\
\hline 11 & Urban liveability: a review. & Pacione (1990) & 26 & 32 & \\
\hline 12 & $\begin{array}{l}\text { More than this: Liveable Melbourne meets } \\
\text { liveable Vancouver. }\end{array}$ & $\begin{array}{l}\text { Holden and Scerri } \\
(2013)\end{array}$ & 8 & 8 & \\
\hline 13 & $\begin{array}{l}\text { Walkable environment in increasing the } \\
\text { liveability of a city. }\end{array}$ & $\begin{array}{l}\text { Shamsuddin, } \\
\text { Hassan (2012) }\end{array}$ & 8 & 17 & \\
\hline 14 & Urban liveability in context & Ley (1990) & 8 & 32 & \\
\hline
\end{tabular}


Table 3: Liveability Research Matrix

\begin{tabular}{|c|c|c|c|c|c|c|c|c|c|c|c|c|c|c|c|c|c|c|c|c|c|c|c|c|c|}
\hline & Research Focus & Authors & & sility & & & $\mathrm{Hes}$ & alth $c_{\text {: }}$ & & Cult & $\operatorname{ire~\& }$ & Env & ronn & ent & & & & & Inf & astru & uctur & & & & \\
\hline & & & 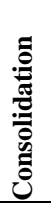 & 产 & 竞 & $\stackrel{\Xi}{\underline{\underline{E}}}$ & 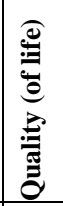 & 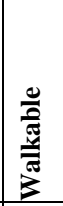 & 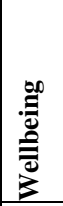 & 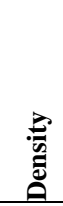 & 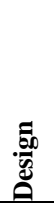 & 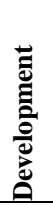 & 离 & 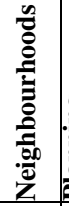 & 里 &  & 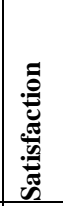 & 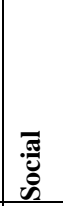 & 昜 & $\frac{\mathscr{\Xi}}{\mathscr{n}}$ & : & 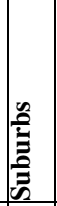 & 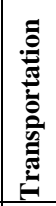 & 20 & 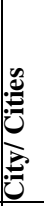 \\
\hline 1 & $\begin{array}{l}\text { Synthesize of liveability concept with social } \\
\text { determinants of wellbeing and liveability indicators }\end{array}$ & Badland, (2014); & & & & $\sqrt{ }$ & & & $\sqrt{ }$ & & $\sqrt{ }$ & & & & & & & $\sqrt{ }$ & & & $\sqrt{ }$ & & & $\sqrt{ }$ & \\
\hline 2 & $\begin{array}{l}\text { The relationship between street design and traffic in } \\
\text { urban neighbourhood and their influence on social } \\
\text { relationship }\end{array}$ & $\begin{array}{l}\text { Sauter and } \\
\text { Huettenmoser (2008); } \\
\text { Adam.M and Ahmed } \\
\text { A (2016) }\end{array}$ & & & & & & $\sqrt{ }$ & & & $\sqrt{ }$ & & $\sqrt{ }$ & $\sqrt{ }$ & & & & $\sqrt{ }$ & & $\sqrt{ }$ & $\sqrt{ }$ & & $\sqrt{ }$ & $\sqrt{ }$ & \\
\hline 3 & $\begin{array}{l}\text { The prospect for transforming important urban } \\
\text { infrastructure systems, such as transport, waste, } \\
\text { water, and energy }\end{array}$ & Newton (2012) & & & $\sqrt{ }$ & & & & & & & $\sqrt{ }$ & $\sqrt{ }$ & $\sqrt{ }$ & & & & & & & & & & $\sqrt{ }$ & \\
\hline 4 & $\begin{array}{l}\text { The paper emphasized on how social communal } \\
\text { life is influenced by the design of an urban layout }\end{array}$ & $\begin{array}{l}\text { Aini. M. A et. al } \\
(2016), \\
(2010)\end{array}$ & & & & & $\sqrt{ }$ & & & $\sqrt{ }$ & $\sqrt{ }$ & & & & $\sqrt{ }$ & & & $\sqrt{ }$ & $\sqrt{ }$ & $\sqrt{ }$ & & $\sqrt{ }$ & & $\sqrt{ }$ & \\
\hline 5 & $\begin{array}{l}\text { The study examined how best to utilize late-night } \\
\text { centres to resolve the conflict of liveability in a city }\end{array}$ & $\begin{array}{l}\text { Roberts and Turner } \\
(2005)\end{array}$ & & $\sqrt{ }$ & & & & & & & & & & & & & & & & & & & & $\sqrt{ }$ & $\sqrt{ }$ \\
\hline 6 & $\begin{array}{l}\text { The study proposed how underground space could } \\
\text { be improved to support a more liveable city }\end{array}$ & Hunt, Makana (2016) & & & $\sqrt{ }$ & & & & & & & $\sqrt{ }$ & & & & $\sqrt{ }$ & & & $\sqrt{ }$ & $\sqrt{ }$ & & & & $\sqrt{ }$ & $\sqrt{ }$ \\
\hline 7 & $\begin{array}{l}\text { The study investigates neighbourhood satisfaction } \\
\text { in a densely populated setting within a city to } \\
\text { improve its liveability }\end{array}$ & Howley, Scott (2009) & $\sqrt{ }$ & & $\sqrt{ }$ & & $\sqrt{ }$ & & & $\sqrt{ }$ & & $\sqrt{ }$ & $\sqrt{ }$ & $\sqrt{ }$ & $\sqrt{ }$ & & $\sqrt{ }$ & $\sqrt{ }$ & $\sqrt{ }$ & & & & & $\sqrt{ }$ & \\
\hline 8 & $\begin{array}{l}\text { The paper makes a comparison between two } \\
\text { suburbs setting for a better understanding of how } \\
\text { liveability is affected by urban liveability }\end{array}$ & $\begin{array}{l}\text { McCrea and Walters } \\
\text { (2012) }\end{array}$ & $\sqrt{ }$ & & & & & & & & & & & $\sqrt{ }$ & & & & & $\sqrt{ }$ & & & $\sqrt{ }$ & & $\sqrt{ }$ & \\
\hline 9 & $\begin{array}{l}\text { The study looked at the intersection between } \\
\text { liveability and sustainability }\end{array}$ & Newton (2007) & & & $\sqrt{ }$ & & & & & & & & $\sqrt{ }$ & & & & $\sqrt{ }$ & & & & & & & $\sqrt{ }$ & \\
\hline 10 & $\begin{array}{l}\text { This study is related to a walkable environment } \\
\text { within a liveable city }\end{array}$ & $\begin{array}{l}\text { Adam. M. et.al } \\
\text { (2016), Shamsuddin, } \\
\text { S. et. al (2012) }\end{array}$ & & $\sqrt{ }$ & & $\sqrt{ }$ & & $\sqrt{ }$ & $\sqrt{ }$ & & & & $\sqrt{ }$ & & & & & & & & & & $\sqrt{ }$ & $\sqrt{ }$ & $\sqrt{ }$ \\
\hline
\end{tabular}




\subsection{Top authors keywords distribution analysis}

Author's keywords distribution is becoming a frequent way of evaluating scientific research in recent years (Chiu et al., 2007; Xie et al., 2008). Using a web-based reading and analysis environment for the digital text we imported the top 10 articles selected for preliminary analysis as shown in Table 2. Prevalent keywords from the highly cited and top articles were then revealed in Figure $6 \mathrm{~b}$. Thus, the most frequently used words are presented to guide future researchers in the field (see Table 3 ).

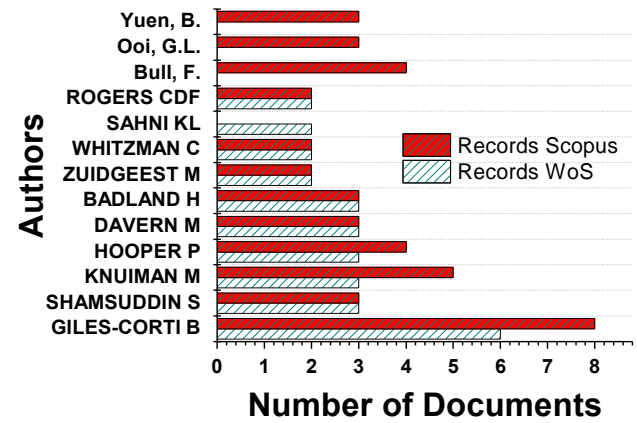

Figure 6: (a) Most productive authors

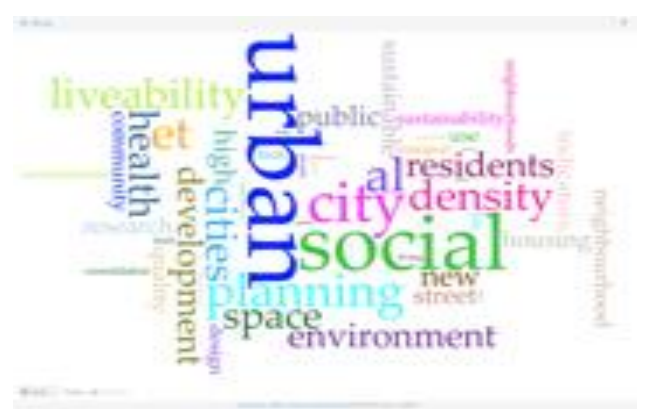

Figure 6: (b) The keywords distribution of the top article

\section{DISCUSSIONS}

This research not only gives an overview of the liveability issues but also how the topic is advancing in the scientific world. Since research, highlighting liveability in the Scopus database is not prevalent before 1980 only $1.84 \%$ as shown in Figure 1, we zoomed into the publication year range 1980 upwards see Figure 2. Moreover, the period corresponds to the year Thomson Reuter's Web of Science (WoS) attained readability profile. Additionally, articles published in the Scopus database before 1980 are either not cited (six articles), cited only once (four articles), or cited twice (two articles). Only two articles received six and nineteen citations in the liveability field before 1980. However, these cited articles are in the subject areas of the human mind and nutrition rather than urban liveability. Notably, it is reasonable to assume that the urban liveability topic is only prevalent after 1980. Outstandingly, $85.5 \%$ of articles published in the three and a half decades studied are concentrated in the 2005-2015 decade, 2015 being the most prolific year (see Figure 2).

Results for the document's type in this field also revealed that publications from articles and reviews amounted to $71.71 \%$ in the WoS. Equally, the Scopus database, articles, article in press and reviews collectively make up $(70.54 \%)$ as shown in the highlighted area in Table 1. Finding reveals that the journal article is typically rated higher in the scientific community. In the liveability field, books are uncommon and articles are prevalent. These mean liveability urban researchers ought to publish more books, while conferences are desired to strengthen international collaboration.

Subject characterization and classification matrix provide a baseline to assess research output by assigning a journal to more than one category and subject area. Social science category covered a wider coverage in liveability field than any other. Thus, our findings confirm the assertion that to ensure urban areas are well placed to meet the growing social challenges and liveability requirement, the compartmentalized analyses that were previously treated in isolation ought to ensure interconnectivity between different domains (Newton, 2012). This is reflected in the fact that social science domain is predominant in our finding yet the content of the outstanding research output is hardly socially inclined. The most outstanding areas of research are the environmental science ecology, Engineering, and business economics. Agriculture/biological science, biomedical science medicine, material science, and art and humanities are among the under-researched areas in liveability domain (Figure 3a), and therefore are areas with high fruition coefficient in liveability research that can be taken into consideration by the novice researchers.

Previous studies have shown that institutional research funding translates into research performance (Auranen and Nieminen, 2010; Muscio et.al, 2013). In this study, the institutional performance of the National University Singapore displayed an unparalleled research output in the Scopus in this field as 
shown in Figure 3b, but smallest significance in the WoS class. The University of Melbourne and University Western Australia maintained the most prolific profile in liveability field worthy emulation. University Technology Malaysia followed by the University of Cape Town has the most impressive record among the developing countries that ought to be sustained if not improved (see Figure $3 \mathrm{~b}$ ). Those universities may provide a fertile ground for students, researchers, academics, and scholars, with a worthy partnership for collaborative research because of their performance index. There is a need to determine whether or not what the government is spending on research in those institutions is really affecting their research performance (Islam et al., 2010), and whether the research outcome is translating into a more liveable city in those countries (Palmary et al., 2003).

In a similar vein, countries productivity can be linked to funding availability. Thus, highincome countries emerged the most prolific in this field with Australia, England and the USA enjoying an uneven advantage that might have given birth to their research outcome (see Figure 4). As revealed in the literature, wide ranging factors has made Australia's as high liveability standing (Holden and Scerri, 2013). Australian liveability is however, admittedly, translating into unsustainable resource consumption in the built environment and individual households (Newton, 2012). Top journals in this field significantly use sustainability approach rather than resilient. Thus, more research is required on how to curtail the problem of managing resources using a resilient based approach in Australia and other countries with a similar predicament. Similarly, Malaysia, China, and South Africa are the top developing countries included among the top countries with a high profile in the global liveability research output (see Figure 4). These present an invitation to the researchers from both the developed and developing countries in the field to venture into a collaborative research in the future.

Journals listed under the WoS cover a wider research area of more than $90 \%$ as indicated in (see Figure 5) than those under the Scopus with just $50 \%$ coverage. Cumulatively, Urban Geography is the leading source title followed by the urban design international, and then international development planning review. Town planning, which was the leading journal in the WoS core collection is now in tandem with international development planning review. Probably because of the dual advantage the latter enjoys being in both the WoS and the Scopus category source. It is clear that journals included in the two leading databases may attract more readability than those listed under only one database (see Figure 5).

Citation characteristics across the WoS core collection and Scopus differ largely by subject area. With relatively few exceptions (like environmental science ecology), scienceoriented subject areas (example, agriculture/biological science, biomedical social science medicine, geriatrics gerontology and material science) attract far less citation than social science based (such as public administration, and geography). Similarly, articles in the Scopus attract more citation. Our study revealed Scopus article enjoying greater citation counts both in sciences and social science-oriented fields. However, in the WoS database, the social science-oriented studies are more cited than science based in the field. Our study also confirms the assertion that prior to 1996 Scopus enjoys limited readability profile because it lacks significant coverage (Harzing, 2010). Citation from the Scopus database is a little higher than those from the WoS articles (Table 2). With few notable exceptions (Roberts and Turner, 2005) and (Southworth, 2003), top articles in the WoS are also the top of the Scopus database.

A total number of documents by authors and citation matrix index measured against the average citation per article in the field are a few of the criteria for measuring the author's contribution to the field. Essential Science Indicator (ESI) in the WoS database is intended to distinguish influential individuals, published articles, and productive countries in a field. Thus, under ESI emerged some highly cited articles in this field (Badland et al., 2014; Hunt et al., 2016) and hot articles based on average citation count in the field (Hunt et al., 2016). Article title and citation received by other top authors is presented in Table 2. Liveability Research Matrix established in this research were aimed to guide future research in finding the gap across global context, areas and multidisciplinary.

Liveable Research Matrix summarizes the research focus of the eminent authors and the frequently used keywords in the top cited article (refer Table 3). Urban, liveability, environment, sustainability, and social emerged the most frequently used words in the top articles in the field. Urban, social, city, planning, liveability, environment, health and development are the most frequently expressed keywords of the top 
authors in the field. Top keywords that cut across liveability research articles, but not fully used are transportation, walkability, resiliency, and wellbeing. These keywords may present and guide future liveability research in finding the gap across global context, areas and multidisciplinary.

\section{CONCLUSION}

This paper appraised the global research output on liveability over the period of three and half decades, using bibliometric analysis from two leading databases. To gain a clearer picture of liveability in the scientific knowledge the study identifies and evaluates the productivity of top authors, documents type, journals, countries, affiliations, and sources. Insight gain from the study showed that article characteristics vary across subject area, document type, and publication age. The research presented the characteristics of the influential, highly cited, and hot articles, which include distribution of common keywords in the top journals publishing them. A limited number of countries and authors key institutions emerged productively. The citation has drastically increased with 2015 as the most prolific year. While continuous research interest is prevalent in liveable built environment related field escalate potential collaborations vis-a-vis research areas that received least attention such as urban transportation, health, well-being and resiliency to give a directional trend for future studies. This research further recommends for broadening the horizon of the liveability into issues and challenges in particular context related to the development of the country with emphasising the social cohesiveness, economic viability and environment. Research on liveability is well discussed and covered amongst developed and developing countries however issues and challenges faced by third world countries are more critical to be acknowledged.

\section{ACKNOWLEDGEMENT}

This study is made possible with the sponsorship of University Malaya Research Grand (UMRG) under the Sustainability Science Research Cluster Titled: RP009-2012A and 2012B: Urban Transformation Emerging Kuala Lumpur Towards a Liveable City.

\section{REFERENCES}

Adam, M., Ab Ghafar, N., \& Mustapha, T. (2016). An Investigation of the Significant Criteria of Vegetation Selection and
Planting Arrangement in Designing Urban Nodes, Journal of Design and Built Environment, 16(2).

Adriaanse, S. L. \& Rensleigh, C. (2013). Web of Science, Scopus and Google Scholar: A content comprehensiveness comparison. The Electronic Library, 31(6), pp. 727-744.

Adam, M. \&Ahmed Abubakar, A. (2016) Incorporating Walking In Travel To Work: The Meaning Of Commuting For Kuala Lumpur Community, Journal of The Malaysian Institute Of Planners Special Issue V(2016), Page 89-100

Aini, M. A, Murni, N., \& Aziz, W. N. A. W. A. (2016). Housing Aspirations of the Elderly in Malaysia: A Comparison of Urban and Rural Areas. Journal of Design and Built Environment, 16(2).

Auranen, O., \& Nieminen, M. (2010). University research funding and publication performance- An international comparison. Research Policy, 39(6), pp. 822-834.

Bar-Ilan, J. (2008). Which h-index? A comparison of WoS, Scopus and Google Scholar. Scientometrics, 74(2), pp. 257-271.

Badland, H., et al. (2014). Urban liveability: emerging lessons from Australia for exploring the potential for indicators to measure the social determinants of health. Social Science \& Medicine, 111, pp. 64-73.

Coats, A. J. (2009). Ethical authorship and publishing. International journal of cardiology, 131(2), pp. 149-150

Chiu, W.T., \& Ho, Y.S. (2007). Bibliometric analysis of tsunami research. Scientometrics, 73(1), pp. 3-17.

De Jong, M., et al., (2015). Sustainable-smartresilient-low carbon-eco-knowledge cities; making sense of a multitude of concepts promoting sustainable urbanization. Journal of Cleaner production, 109, pp. 25-38.

Falagas, M.E., et al. (2013). The impact of article length on the number of future citations: a bibliometric analysis of general medicine journals. PLoS One, 8(2) pp. e49476.

Harzing, A.W. (2010). Citation analysis across disciplines: The Impact of different data sources and citation metrics. doi http://www/.harzing.com/data_metrics_com parison. htm.

Gregory A.M., Weinland J. (2016), Timeshare research: A synthesis of forty years of publications. International Journal of Contemporary Hospitality Management, 28 (3) (2016), pp. 438-470

Gul, S., et al., (2015). Research output on Lavender, 2008-2012. European Journal of Integrative Medicine, 7(5), pp. 460-466. 
Hunt, D., et al., (2016). Liveable cities and urban underground space. Tunnelling and Underground Space Technology, 55, pp 820

Howley, P., Scott, M., \& Redmond, D. (2009). Sustainability versus liveability: an investigation of neighbourhood satisfaction. Journal of environmental planning and management, 52(6), pp. 847-864.

Holden, M., \& Scerri, A. (2013). More than this: Liveable Melbourne meets liveable Vancouver. Cities, 31, pp. 444-453.

Islam, T., Merrell, W., \& Seitz, W. (2010). Galveston Futures: Developing a disaster resilient community. Journal of Geography and Regional Planning, 3(1), p. 001-007.

Landström H., Harirchi G., and Åström F. (2012), Entrepreneurship: Exploring the knowledge base. Research Policy, 41 (7) (2012), pp. 1154-1181

Leichenko, R., (2011). Climate change and urban resilience. Current opinion in environmental sustainability, 3(3), pp. 164168.

Levine-Clark, M., \& Gil, E. (2009). A comparative analysis of social sciences citation tools. Online information review, 33(5), pp. 986-996.

Ley D. (1990). Urban liveability in context. Urban Geography, 11(1), pp. 31-35.

McCrea, R., \& Walters, P. (2012). Impacts of urban consolidation on urban liveability: Comparing an inner and outer suburb in Brisbane, Australia. Housing, Theory and Society, 29(2), pp. 190-206

McBurney M. K. \& Novak P. L. (2002). What is bibliometric and why should you care? In: Proceedings of the professional communication conference, pp. 108-114.

Muscio, A., Quaglione, D., \& Vallanti, G. (2013). Does government funding complement or substitute private research funding to universities? Research Policy, 42(1), pp. 63-75.
Newton, P.W. (2007). Horizon 3 planning: meshing liveability with sustainability. Environment and Planning B: Planning and Design, 34(4), pp. 571-575.

Newton, P.W. (2012). Liveable and Sustainable? Socio-Technical Challenges for Twenty-First-Century Cities. Journal of Urban Technology, 19(1), pp. 81-102

Pacione, M. (1990). Urban liveability: a review. Urban geography, 11(1), pp. 1-30.

Pantuliano, S., et al., (2012). Urban vulnerability and displacement: a review of current issues. Disasters, 36(s1), pp. S1S22.

Palmary, I., Rauch, J., \& Simpson, G. (2003). Violent crime in Johannesburg. Emerging Johannesburg: perspectives on the postapartheid city, pp. 101-122.

Raman, S. (2010). Designing a liveable compact city: Physical forms of city and social life in urban neighbourhoods. Built Environment, 36(1), pp. 63-80.

Roberts, M., \& C. Turner (2005). Conflicts of Liveability in the 24-hour City: Learning from 48 Hours in the Life of London's Soho. Journal of Urban Design, 10(2), pp. 171193.

Shamsuddin, S., Hassan, N.R.A., \& Bilyamin, S.F.I. (2012). Walkable environment in increasing the liveability of a city. ProcediaSocial and Behavioral Sciences, 50, pp. 167-178.

Southworth, M. (2003). Measuring the liveable city. Built Environment, 29(4), pp. 343-354.

Sauter, D. \& Huettenmoser, M. (2008). Liveable streets and social inclusion. Urban Design International, 13(2), pp. 67-79.

Xie, S., Zhang, J., \& Ho, Y.S. (2008). Assessment of world aerosol research trends by bibliometric analysis. Scientometrics, 77(1), pp. 113-130. 